УДК 780.616.432:785.74]:781.68.071.2

DOI: https://doi.org/10.33643/kmus.2019.59.03

Дарья Кутлуева,

преподаватель кафедры камерного ансамбля, соискатель кафедры теории музыки

Харьковского национального университета искусств имени И. П. Котляревского https://orcid.org/0000-0002-2751-5720 daryakutlueva@gmail.com

Daria Kutluieva,

Lecturer at the Chamber Ensemble Department, Applicant at the Theory of Music Department, Kharkiv National I. P. Kotlyarevsky University of Arts https://orcid.org/0000-0002-2751-5720 daryakutlueva@gmail.com

\title{
ЖАНРОВЫЕ СЛАГАЕМЫЕ \\ ФОРТЕПИАННОГО КВАРТЕТА И ИХ ОТРАЖЕНИЕ В ИСПОЛНИТЕЛЬСКИХ ИНТЕРПРЕТАЦИЯХ (НА ПРИМЕРЕ КВАРТЕТА № 1 ES-DUR ЛЮДВИГА ВАН БЕТХОВЕНА)
}

Актуальность темы настоящей статьи обусловлена задачами научного изучения жанровых слагаемых фортепианного квартета и их воплощения в современной исполнительской практике. Цель предлагаемой статьи - раскрытие свойств данного жанра в научной и исполнительской практике. Mетоды исследования - жанрово-генетический и компаративный. Фортепианный квартет вбирает в себя свойства струнного квартета, сольного концерта, различные принципы формообразования и камерно-ансамблевого письма. Способом познания данного жанра выступает анализ исполнения избранного сочинения различными коллективами, один из которых демонстрирует квартетное мышление, другой - концертно-виртуозное.

Ключевые слова: фортепианный квартет, камерный ансамбль, жанр, Л. Бетховен, исполнительская интерпретация.

Kutluieva Daria. Genre components of the piano quartet and their reflection in performing interpretations (exemplified by the Quartet № 1 Es-dur by Ludwig van Beethoven). Relevance of the study is the need for scientific research of the genre components of the piano quartet and their implementation in contemporary performing practice. Main objectives of the study is related to the need to disclose the content properties of the genre of the piano quartet and its capture in existing executable interpretations. Methodologies of this research are selected genre-genetic, revealing the 
typological essence of the piano quartet, and comparative, which is due to the formulated topic of the article. Results and conclusions. Numerous scientific studies devoted to the study of the piano quartet, reveal the genetic diversity of this genre, which becomes one of its core features. These include: sufficient independence of votes coming from the trio-principle; the motive detail of the parties, inherent in the string quartet; virtuosity in solo episodes, characteristic of the genre of instrumental concert. The piano quartet arose in 1785 in the works by V. A. Mozart and L. Beethoven. The First quartet Es-dur WoO 36 by L. Beethoven became one of four examples of this genre in his work. Scientists see in it the resemblance with violin sonata's by V. A. Mozart G-dur №379, namely the similarity of compositional solution, musical form and tempo. However, the piano quartet by L. Beethoven has another timbre and texture of composition, which contributes to the synthesis of chamber-quartet and virtuosoconcert properties, which determines his different understanding in performing practice. The «Amadeus Quartet» team with the pianist K. Eschenbach interpret the work, considering the quartet nature of the genre, in the form of equal interaction between the four members of the ensemble. Another approach is shown by the ensemble «Sonore», performing the piano quartet in an emphasized virtuoso manner, demonstrating the solo capabilities of the band members.

Key words: piano quartet, chamber ensemble, genre, L. Beethoven, performing interpretation.

Кутлуєва Дар'я. Жанрові складові фортепіанного квартету та їх відображення у виконавських інтерпретаціях (на прикладі Квартету № 1 Es-dur Людвіга ван Бетховена). Актуальність теми запропонованої статті полягає в необхідності наукового вивчення жанрових складових фортепіанного квартету та їх втілення у сучасній виконавській практиці. Мета дослідження пов'язана 3 потребою у розкритті змістових властивостей жанру фортепіанного квартету та його опанування в наявних виконавських інтерпретаціях. Методами дослідження обрані жанровогенетичний, що розкриває типологічну сутність фортепіанного квартету, та компаративний, який обумовлений сформульованою темою статті. Результати дослідження. Численні наукові дослідження, присвячені вивченню фортепіанного квартету, розкривають генетичну множинність даного жанру, що стає однією з його родових ознак. До них відносяться: достатня самостійність голосів, що йде від тріо-принципу; мотивна деталізація партій, притаманна струнному квартету; віртуозність у сольних епізодах, характерна для жанру інструментального концерту. Фортепіанний квартет виник 1785 року у творчості В. А. Моцарта та Л. Бетховена. Перший квартет $E s-d u r$ WoO 36 Л. Бетховена став одним із 
чотирьох зразків даного жанру у його творчості. Науковці вбачають у ньому риси скрипкової сонати В. А. Моцарта $G-d u r$ № 379, а саме схожість композиційного рішення, музичної форми та темпу. Проте фортепіанний квартет Л. Бетховена має інший темброво-фактурний склад, який сприяє синтезу камерно-квартетних та віртуозно-концертних властивостей, що обумовлює різні його розуміння у виконавський практиці. Колектив «Амадеус-квартет» 3 піаністом К. Ешенбахом трактують названий твір, враховуючи квартетну природу жанру, у вигляді рівноправної взаємодії чотирьох учасників ансамбля. Інший підхід демонструє ансамбль «Соноре», що виконує фортепіанний квартет у підкреслено віртуозній манері, демонструючи сольні можливості учасників колективу.

Ключові слова: фортепіанний квартет, камерний ансамбль, жанр, Л. Бетховен, виконавська інтерпретація.

Постановка проблемы. Жанр фортепианного квартета, довольно широко представленный в камерно-инструментальном творчестве различных композиторов от В.А. Моцарта до А. Шнитке и постоянно привлекающий исполнителей, мало изучен в научной и методической литературе. В настоящее время наблюдается оживление исследовательского интереса к феномену фортепианного квартета, о чем свидетельствуют посвященные ему изыскания Л. М. Повзун и Н. К. Самойловой, касающиеся генезиса жанра [4; 6]. Материалы по теории и истории фортепианного квартета содержатся также в исследованиях И. Бялого, Т. Гайдамович, Л. Кириллиной, И. Польской, B. Smallmon $[1 ; 2 ; 3 ; 5 ; 7]$. Сопоставление взглядов на него названых авторов убеждает в дискуссионности вопроса о происхождении данного жанра и его родовых качествах, что побуждает к дальнейшей разработке этого вопроса. Его рассмотрение имеет не только научно-теоретический, но и исполнительско-практический аспект, поскольку от трактовки ансамблевых взаимодействий партнеров во многом зависит жанровая модальность представляемого произведения.

Актуальность темы настоящей статьи обусловлена возрастающим интересом музыкальной науки к проблемам камерно-инструментального ансамбля. Несмотря на появление крупных монографических исследований И. Бялого [1], И. Польской [5], Л. Повзун [4], многие аспекты изучения данной сферы композиторского и исполнительского творчества остаются неосвещенными. В частности, современная наука находится лишь на пути осмысления жанровых свойств фортепианного квартета. Произведения этого типа имеют богатую историю, которая 
нуждается в особом методологическом подходе, связанном с их спецификой. Немаловажно также наличие существенного разрыва между теоретическим знанием и практическим воплощением фортепианного квартета в пространстве музыкальной культуры конца XX-XXI веков.

Научная новизна полученных результатов. Жанр фортепианного квартета представлен в виде системы исторически сложившихся явлений, которые раскрываются при помощи не только музыкально-теоретического, но и исполнительского анализа.

Цель предлагаемой статьи заключается в сравнительной характеристике интерпретаций фортепианного квартета Es-dur WoO 36 Л. Бетховена современными исполнительскими коллективами как способа раскрытия многоликости природы данного жанра.

Для достижения поставленной цели сформулированы следующие задачи:

- на основе изучения научных источников систематизировать современные представления о жанровом содержании фортепианного квартета;

- исследовать принципы камерного письма Л. Бетховена в фортепианном квартете $E s-d u r$ WoO 36;

- осуществить с избранных позиций сравнительный анализ исполнительских интерпретаций названного произведения.

Методы исследования. В качестве основы для раскрытия заявленной темы используется жанрово-генетический подход к фортепианному квартету, поскольку в научной литературе именно данный аспект жанра обнаруживает свойство дискуссионности. Например, И. Бялый [1] указывает на влияние трио-принципа в становлении жанра, Н. Самойлова [6] видит происхождение этого жанра из семейства ансамблей с участием клавира, Л. Повзун [4] указывает на струнно-квартетный принцип письма как прототип ансамблевой фактуры фортепианного квартета. В результате изучения научной литературы, раскрывающей генетические основы жанра, можно сделать вывод, что родовая сущность фортепианного квартета заключается в его многоликости. Для правомерности данного вывода предпринимается сравнительный анализ некоторых интерпретаций избранного сочинения, для чего используется компаративный подход. Обращение к нему служит дополнительным средством осмысления типологических и историко-генетических свойств фортепианного квартета. С этой точки зрения представляется целесообразным изучение произведения, принадлежащего к данному жанру, в период его кристаллизации в творчестве Л. Бетховена. Другой аспект компаративного подхода заключается в сравнительном анализе нотных партитур фортепианного квартета Л.Бетховена и его прообраза: 
скрипичной сонаты В. А. Моцарта, что позволяет выявить специфику ансамблевого письма в возникающем новом жанре фортепианного квартета.

Результаты исследования. По мнению исследователей камерноинструментальных ансамблей с участием фортепиано, квартетная разновидность данной области творчества возникла исторически позже дуэтной сонаты и трио, то есть в последней трети XVIII века. Если иметь в виду первые образцы этого жанра, авторами которых принято считать В. А. Моцарта и Л. Бетховена, то время рождения фортепианного квартета можно определить совершенно точно: 1785-1786 годы. К этому моменту откристаллизовались струнный квартет, родственный фортепианному по количественному показателю, и фортепианный концерт, близкий ему по принципу «солист - группа инотембровых инструментов», повлиявшие на возникновение жанра фортепианного квартета. В исследовательских источниках [1] указывается также на воздействие трио-сонаты, одного из важнейших жанров барочной музыки, особенностью которого был триопринцип. Этот принцип предполагал такой тип инструментального трехголосия, в котором партии обладали самостоятельностью и индивидуализированностью, что стало характерной чертой и бетховенских фортепианных квартетов как одних из первых образцов жанра.

Фортепианные квартеты Л. Бетховена возникли в том же 1785 году, что и в композиторской практике В. А. Моцарта, впервые обратившегося к этому жанру. Данный период творчества Л. Бетховена принято называть боннским, что закрепило за первыми тремя фортепианными квартетами название «Боннские». В научной литературе отсутствует информация, свидетельствующая о том, что начинающий автор был знаком с фортепианными квартетами своего старшего современника. Однако Л. Кириллина указывает на то, что в качестве своего рода «моделей» для Л. Бетховена в создании фортепианных квартетов выступили сонаты для скрипки и фортепиано В. А. Моцарта, в частности, для фортепианного квартета $E s$-dur WoO 36 - соната $G$-dur № 379 (по Кёхелю).

Доказательством сходства данного фортепианного квартета с названой сонатой для скрипки и фортепиано $\mathrm{B}$. А. Моцарта для Л. Кириллиной служит поразительное совпадение композиционного решения обоих сочинений. Они открываются развернутым разделом в темпе Adagio assai, после чего следуют быстрый раздел сонатной формы и тема с вариациями, обозначенная cantabile. Однако Л. Бетховен пишет фортепианный квартет, и в отличие от моцартовской сонаты, где тема излагается вначале фортепианным соло, а затем скрипкой, и далее они ведут по очереди беседу, у него все участники квартета включаются сразу 
в изложении ведущего материала. Такой фактурно-ансамблевый прием раскрывает «промежуточность» жанра фортепианного квартета между камерностью трио и «репрезентативностью» концерта. Несмотря на коллективность в экспонировании исходной мысли сочинения, о своей доминирующей позиции сразу же заявляет клавишный инструмент. Ему поручается, как и в сонате у В.А. Моцарта, мелодический рельеф, а струнные поддерживают его гармоническими вертикалями, которые дублируют то ритмический рисунок верхнего голоса фортепиано, то линию его баса. При этом интересно отметить, что у Л. Бетховена уже в этой ранней партитуре появляется много $s f$ и $f$, отмечающих выразительную речевую и вокальную интонацию гораздо рельефнее, нежели у его старшего современника.

В продолжение концертной линии квартета в побочной партии инициатива передается струнной группе. Мелодический рельеф темы темброво осмысливается диалогом скрипки и альта в виде краткой имитации с последующей синхронизацией партий. Тем временем виолончель обеспечивает гармоническую опору, на которую наслаиваются аккордовые фигурации и вертикали. Благодаря такому фактурному приему достигается обертоновая полнота ансамблевой фактуры, диапазон которой охватывает более трех октав. Складывается интересное распределение функций голосов в соответствии с ансамблевой природой фортепианного квартета: скрипка и альт выступают со своим соло, виолончель обеспечивает гармонический фундамент, а рояль откликается как на гармонию, так и на мелодический рисунок темы, выступая как бы посредником между функциями голосов струнного трио. Затем с короткой тематической репликой в диалог со скрипкой включается и виолончель, что свидетельствует о попытке Л. Бетховена нащупать пути индивидуализации партии этого инструмента, как правило, ограниченной в то время ролью basso continuo. Показательно, что именно данный композитор, по сути, станет родоначальником жанра виолончельной сонаты в камерной музыке XIX века. В заключительной партии, исходным моментом которой служит начальный оборот побочной, фортепиано возвращается к роли ведущего инструмента. Лишь в последних четырёх кадансовых тактах к солирующим скрипке и альту добавляется в унисон верхний голос рояля, обогащая их новой тембровой краской.

Разработка целиком посвящена развитию побочной темы. Она начинается вновь диалогом скрипки и альта при гармонической и ритмической поддержке фортепиано и виолончели; в последующих тактах в диалог вступают верхний голос рояля и скрипка на фоне выдержанных 
аккордовых вертикалей виолончели и альта, и ритмически упругий, в духе аккомпанемента в контрдансах, нижний голос фортепиано. Эти два проведения диалогов Л. Бетховен использует с целью достижения тембрового разнообразия и приближения характера звучания двух разнородных инструментов (фортепиано и струнных) друг к другу, так как артикуляция и указания $f$ и $p$ под каждой нотой предполагают одинаковую манеру произношения тематического материала и реплик. Благодаря активизации мелодической инициативы всех инструментов, их дилогическим перекличкам возникает аналогия с разработочным типом развития в сонатно-симфонических формах. Совершенно в соответствии с барочным контрастно-составным принципом формообразования Л. Бетховен завершает Adagio assai на доминанте (B-dur), продлевая звучание ферматой и создавая тем самым переход к Allegro con spirito es-moll.

Интересно, что ладотональное соотношение вступления и быстрого раздела первой части, а также их темповые обозначения аналогичны моцартовским. В то же время, Л. Бетховен добавляет к ним новые характеристики: Adagio assai, Allegro con spirito, что предвосхищает излюбленные композитором в последующие периоды творчества дополнительные эпитеты, уточняющие темповые рекомендации.

Как и медленное вступление первой части квартета, ее быстрый раздел связывается композитором с тембром фортепиано. В партии правой руки излагается мелодия на фоне пульсирующих синкопированных аккордов всех струнных, ритмического остинато виолончели и нижнего голоса фортепиано. В кадансовой зоне возникает унисонное тутти, приводящее к связующей теме, начинающейся нюансом $f f$. Как и в Adagio assai, связующая партия переводит не только в побочную тональность, но и в новую тему. Автор использует прием производного тематического контраста, который в дальнейшем во многом определит его композиторский метод. Речь идет в данном случае о восходящем движении по звукам трезвучия либо квартсекстаккорда. Гармонический переход к побочной тональности $b$-moll выдержан в характерном пунктирном ритме, который заимствует побочная тема. Она усиливает ритмическую упругость музыки сонатного allegro и звучит поочередно у всех голосов квартета. Заключительная партия вносит стабильность в своеволие инструментов, увещевая их «вздохами» на $p$. При этом каждый голос обладает собственным ритмическим рисунком: у скрипки - это четырёхтактовые секундовые ходы, у рояля - мягкие нисходящие терцовые реплики в каждом такте, у альта - гармоническая фигурация, опевающая основной тон со слабого времени (пауза на каждую первую долю). Виолончель 
оформляет гармоническими шагами всю конструкцию в унисон с басами фортепиано. Однако завершается экспозиция бурными взлетающими пассажами рояля в духе концертного пианизма $(f)$ и галантным кадансовым «приседанием» в манере В. А. Моцарта и Й. Гайдна.

Разработка невелика, выдержана целиком на $p$, как бы оттеняя страстный драматический характер большинства тем экспозиции. В первых восьми тактах складывается диалог между скрипкой, играющей вариант initio главной темы в обращении, и настороженных реплик рояля. Здесь господствует отрывистый штрих, доминантовая гармония, что создает ситуацию ожидания. В последующих четырнадцати тактах преобладает «успокаивающая» тема заключительной партии, концентрируясь в хоральной фактуре всех инструментов $p$, decrescendo. Небольшая связка подводит к репризе, которая вновь врывается страстным $f$. В ней в целом сохраняются тематизм и присущие экспозиции ансамблевые соотношения с переходом побочной и заключительной партий в основную тональность, что соответствует законам сонатного allegro. Вместе с тем, композитор вносит фактурные элементы, отсутствовавшие в первом разделе сонатной формы. Так, в заключительной партии виртуозные рулады фортепиано расширены, что усиливает концертный характер трактовки инструмента в фортепианном квартете.

Вторая часть (Es-dur, cantabile) - тема с вариациями, практически точно следует моцартовской модели цикла. Разница заключается только в количестве голосов участников ансамбля и, соответственно, в количественном и тембровом оформлении вариаций.

Форма вариаций, избранная Л. Бетховеном вслед за В. А. Моцартом для заключительной части, благодатна для ансамблевого жанра, поскольку она позволяет раскрепостить каждый из инструментов-участников, выдвинув его на первый план, вследствие чего возникает парад их возможностей. $\mathrm{C}$ другой стороны, широко понимаемый принцип диалогичности напоминает о концертной соревновательности, поскольку в фортепианном квартете помимо мелодических голосов участвует инструмент, наделённый многоголосной фактурой, что предполагает сопоставление и противопоставление темброво-звуковых объемов. Не менее существенной представляется предрасположенность строгой вариационной формы к демонстрации как композиторского изобретательность в работе с темой с сохранением её целостности посредством разнообразных способов изложения, так и ансамблевоисполнительского - гибкость сопряжения ролевых функций, мастерства. В своем юношеском сочинении Л. Бетховен ещё не предпринимает попыток 
семантического и композиционного расширения вариационной формы, её сближения, с одной стороны, с сюитой, как в фортепианных вариациях op. 34 и ор. 120 (на тему А. Диабелли), с другой - сонатно-симфонической логикой, как в 32 вариациях $W o O 80$ или финале «Героической» симфонии. С этой точки зрения он предстаёт в фортепианном квартете Es-dur непосредственным продолжателем венского классического стиля.

С моцартовским образцом корреспондируют в этом плане первая, вторая и пятая вариации. Первая вариация в сонате В. А. Моцарта целиком отдана фортепиано. В квартете Л. Бетховена она также поручена роялю, но еe окружают струнные pizzicato, тем самым создавая новый тембровозвуковой колорит. Вторая - как и у В. А. Моцарта, изложена триолями шестнадцатых и отдана скрипке. Третья вариация в фортепианном квартете Л. Бетховена поручена солирующему альту, который проводит ее уже в более мелком ритмическом варианте тридцатьвторыми. Четвертая вариация демонстрирует солирующую виолончель. Пятая вариация es-moll корреспондирует с четвертой минорной вариацией В. А. Моцарта: тот же пунктирный рисунок темы и драматический характер. В шестой вариации и заключении возвращаются приемы совместной игры, соответственно, орнаментальное варьирование с разным ритмическим рисунком, унисоны фортепиано, скрипки и виолончели (неполное tutti) и фигурации альта. В заключение звучит унисон фортепиано, скрипки и виолончели, а альт заполняет танцевальную тему фигурациями.

Таким образом, в фортепианном квартете № 1 Л. Бетховена ясно прослеживаются те генетические составляющие жанра, которые выявлены в исследовательской литературе.

Ансамблевые коллективы, исполняющие фортепианные квартеты Л. Бетховена, опираются на один из описанных жанровых прототипов. Интерпретации бетховенских квартетов можно условно разделить на две группы: ансамбли, выявляющие либо квартетную, либо концертновиртуозную линию развития жанра.

В данной статье рассматривается интерпретация фортепианного квартета Es-dur WoO 36 Л. Бетховена двумя коллективами: пианистом К. Эшенбахом (Германия) и струнным трио участников «Амадеус-квартета» (Британия), представляющими первую группу; а также фортепианным квартетом «Соноре» (Россия), представляющим вторую группу.

Трактовка данного произведения первым из названных коллективов в большей степени выявляет квартетную природу жанра, так как исполнители-струнники являются участниками устоявшегося коллектива «Амадеус-квартет», имеющего богатый концертный и репертуарный опыт. 
Они направляют логику своего повествования в сторону равноправного взаимодействия четырех участников ансамбля, где все голоса паритетны и гармонично соразмерны.

Фортепианный квартет «Соноре» специализируется на исполнении фортепианных квартетов, в связи с чем можно говорить о большом опыте его участников в освоении репертуара данного жанра, охватывающего произведения разных исторических эпох и индивидуальных стилей. Коллектив демонстрирует концертный подход к интерпретации бетховенского квартета, что выявляется в демонстрации подчеркнутовиртуозных возможностей инструментов каждым участником коллектива и репрезентативностью высказывания. Заметим, что современная практика исполнения фортепианных квартетов имеет тенденцию к объединению солистов-инструменталистов в ансамбль, что не всегда благоприятно сказывается на отражении логики композиторской мысли и часто ведет к излишней концертизации жанра, где каждый участник демонстрирует свои возможности, выходя за рамки камерности жанра.

Bbыводы. Изученный научный материал дает основание для вывода о том, что в творчестве композиторов-классиков В. А. Моцарта и Л. Бетховена был апробирован новый для рассматриваемой эпохи тип ансамбля - фортепианный квартет, и завершился этап его формирования, который определил путь дальнейшей эволюции данного жанра. Учеными установлено, что генетическими истоками фортепианного квартета стали трио-соната, клавирный концерт с аккомпанементом струнного ансамбля и струнный квартет. Исследователи отмечают воздействие на композиционную модель фортепианного квартета принципов формирующейся сонатности, с одной стороны, и концертной практики, с другой. Принципы письма уже сложившихся жанров (исполнительский состав, структура цикла, типы инструментовки и фактуры) повлияли на принцип организации фактуры фортепианного квартета. Основополагающими приемами письма являются достаточная самостоятельность голосов, идущая от трио-принципа, мотивная детализация партий, унаследованная от струнного квартета, и виртуозность в сольных эпизодах инструментов, пришедшая из жанра концерта. Сравнение фортепианного квартета Л. Бетховена с его моцартовским прообразом (соната для скрипки и фортепиано $G$-dur № 379) позволило установить существенные различия в ансамблевом письме, присущем, соответственно, камерно-ансамблевому дуэту и фортепианному квартету. Тем самым раскрывается специфика последнего с точки зрения распределения ансамблевых ролей, фактурной организации как 
существенных показателей данного жанра. Выявление названных типологических свойств раскрывается в исполнительских интерпретациях, которые так же многолики, как и сам жанр. Их можно условно разделить на следующие группы: первая группа - ансамбли, выявляющие квартетную линию развития жанра («Амадеус-квартет» совместно с пианистом К. Эшенбахом), в торая группа - концертно-виртуозную (ансамбль «Соноре»).

1. Бялый И. Из истории фортепианного трио. Москва : Музыка, 1989. 94 с.

2. Гайдамович Т. А. Инструментальные ансамбли. Москва : Музгиз, 1963. 56 с.

3. Кириллина Л. Бетховен. Жизнь и творчество : в 2 т. Том 2. Москва : Московская консерватория, 2009. 536 с.

4. Повзун Л. І. Камерний ансамбль : $з$ історії розвитку ансамблевого виконавства й становлення камерно-інструментальних жанрів. Одеса : Печатний дім, 2007. 213 с.

5. Польская И. И. Камерный ансамбль : История, теория, эстетика : монография. Харьков : ХГАК, 2001. 396 с.

6. Самойлова Н. К. Фортепианный квартет в русской музыке : автореф. дис. ... канд. искусствоведения : 17.00.02. Оренбург, 2011. 17 с.

7. Mason D. G. The quartets of Beethoven. Oxford : Oxford University Press, 1947. 294 p.

8. Robertson A. Chamber music. London : Penguin Books, 1970. 427 p.

9. Smallman B. The Piano Quartet and Quintet: Style, Structure, and Scoring. London: Oxford University Press, 1994. 193 p.

\section{References}

1. Bialy, I. (1989). From the history of the piano trio. Moscow: Muzyka [in Russian].

2. Gaidamovich, T. (1963). Instrumental ensembles. Moscow: Muzgiz [in Russian].

3. Kirillina, L. (2009). Beethoven. Life and creativity. Vol. 2. Moscow: Moskovskaya konservatoriya [in Russian].

4. Povzun, L. (2007). Chamber Ensemble: on the history of the ensemble performance and the formation of chamber and instrumental genres. Odessa: Pechatnyiy dim [in Ukrainian].

5. Pol'skaya, I. (2001). Chamber Ensemble: History, Theory, Aesthetics. Kharkiv: Kharkiv State Academy of Culture [in Russian].

6. Samoilova, N. (2011). Piano quartet in Russian music. Extended abstract of PhD thesis. Orenburg [in Russian].

7. Mason, D. (1947). The quartets of Beethoven. Oxford: Oxford University Press [in English].

8. Robertson, A. (1970). Chamber music. London: Penguin Books [in English].

9. Smallman, B. (1994). The Piano Quartet and Quintet: Style, Structure, and Scoring. London: Oxford University Press [in English]. 